\title{
Curcumin suppresses cell proliferation through inhibition of the Wnt/ $\beta$-catenin signaling pathway in medulloblastoma
}

\author{
MISI HE ${ }^{*}$, YU LI $^{2 *}$, LI ZHANG $^{1}$, LONGJIANG LI ${ }^{1}$, YI SHEN $^{1}$, LING LIN ${ }^{1}$,

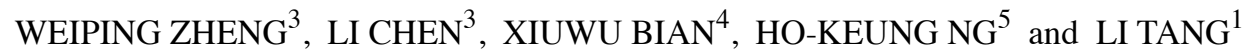 \\ ${ }^{1}$ Department of Pathophysiology, Chongqing Medical University, Chongqing; ${ }^{2}$ Department of Pathology, \\ Insititute of Neuroscience, Chongqing Medical University, Chongqing; ${ }^{3}$ Experimental and Teaching Center, \\ Chongqing Medical University, Chongqing; ${ }^{4}$ Institute of Pathology and Southwest Cancer Center, \\ Southwest Hospital, Third Military Medical University, Chongqing; ${ }^{5}$ Department of Anatomical \\ and Cellular Pathology, The Chinese University of Hong Kong, Hong Kong, SAR, P.R. China
}

Received February 2, 2014; Accepted April 23, 2014

DOI: 10.3892/or.2014.3206

\begin{abstract}
Recently, the survival rate of medulloblastoma patients has greatly improved; yet, patients undergoing current treatment regimes suffer from serious therapy-related sideeffects. The aim of the present study was to investigate the anticancer effects of curcumin on medulloblastoma cells by testing its capacity to suppress proliferation and regulate the Wnt/ $\beta$-catenin pathway. In the present study, cell proliferation was determined by MTT assay. Cell cycle was observed by flow cytometry. The changes in the Wnt/ $\beta$-catenin pathway were analyzed by immunofluorescence, western blot analysis and RT-PCR. Curcumin treatment resulted in a dose- and time-dependent inhibition of proliferation in the medulloblastoma cell line. Curcumin treatment arrested the cell-cycle at the $\mathrm{G}_{2} / \mathrm{M}$ phase. Furthermore, curcumin treatment led to activation of GSK-3 $\beta$, reduced expression of $\beta$-catenin and its downstream target cyclin D1. The attenuation of the $\mathrm{Wnt} / \beta$-catenin pathway was due to the loss of nuclear $\beta$-catenin. In conclusion, curcumin can inhibit cell growth by suppressing the Wnt/ $\beta$-catenin signaling pathway, and it has the potential to be developed as a therapeutic agent for medulloblastoma.
\end{abstract}

\section{Introduction}

Medulloblastoma (MB), a cancer of the cerebellum, is the most common malignant embryonal neuroepithelial tumor in chil-

Correspondence to: Dr Li Tang, Department of Pathophysiology, Chongqing Medical University, No. 1 Yixueyuan Road, Chongqing 400016, P.R. China

E-mail: tanglicq@126.com

${ }^{*}$ Contributed equally

Key words: medulloblastoma, Wnt signaling pathway, $\beta$-catenin, curcumin dren. It is one of the leading causes of morbidity and mortality in pediatric cancer (1). Recently, the survival rates have shown improvement; yet, patients undergoing current treatment regimes suffer from serious therapy-related side-effects, such as loss of hearing and cognitive impairment (2). Due to its high mortality rate and the post-treatment disabilities of current therapies, there is an urgent need for the development of nontoxic and efficient agents for MB.

Curcumin (diferuloymethane, $\mathrm{C}_{21} \mathrm{H}_{20} \mathrm{O}_{6}$ ), a yellow natural product, is a non-toxic, major component of the spice turmeric derived from the plant Curcumin longa (3). It has shown a wide range of pharmacological activities including anti-inflammatory, anti-oxidative, immunomodulating, anti-atherogenic and anticarcinogenic effects $(4,5)$. For the last few decades, in vivo and in vitro studies have demonstrated the ability of curcumin to effectively inhibit tumor growth (6). This antitumor capacity of curcumin is associated with its property to interact with a wide variety of signaling pathways and the ability to regulate their activity (5). However, the precise molecular mechanisms of curcumin-mediated inhibition of tumor growth need to be elucidated.

Recent studies have shown that carcinogenesis and progression of $\mathrm{MB}$ are related to multiple molecular dysfunctions. The major molecular pathways known to have important roles in cerebellum development, include Wnt/ $\beta$-catenin, Sonic Hedgehog (SHH), Notch and Akt/nuclear factor- $\kappa \mathrm{B}$ $(\mathrm{NF}-\kappa \mathrm{B})(7,8)$. The Wnt signaling pathway contributes to the control of processes involved in embryonic development including cell proliferation, differentiation and oncogenesis (9). $\beta$-catenin is a key activator of the canonical Wnt signaling pathway. In the absence of Wnt stimulation, $\beta$-catenin is complexed with adenomatosis polyposis coli (APC) and scaffold protein axis inhibition protein (Axin), and is phosphorylated by glycogen synthase kinase $3 \beta$ (GSK$3 \beta$ ), leading to ubiquitination and proteasome-dependent degradation. In the presence of Wnt stimulation, Wnt ligands bind to the family of cell surface Frizzled receptors and low density lipoprotein receptor-related protein (LRP), resulting in an intracellular cascade allowing $\beta$-catenin release from 
phosphorylation by GSK-3 $\beta$ and degradation by proteosome. Then the accumulated $\beta$-catenin translocates into the nucleus and binds to the T cell factor/lymphoid enhancer factor (TCF/ LEF) transcription factors inducing unabated transcription of several oncogenes, including cyclin D1 and c-Myc, resulting in enhanced cellular proliferation (10). Aberrant expression of $\mathrm{Wnt} / \beta$-catenin signaling components and inappropriate activation of Wnt signaling have been found in a variety of human cancers (11). Mutations in Wnt signaling complex have been identified in $\mathrm{MB}$, accounting for $25 \%$ of sporadic $\mathrm{MB}$ (12). These include activating mutations in CTNNB1 (which codes for $\beta$-catenin) and inactivating mutations in APC and Axin $(13,14)$. In fact, the abnormal accumulation and location of $\beta$-catenin play a crucial role in all of these mutations. Thus, inhibiting the expression and nuclear translocation of $\beta$-catenin can be a potential therapy for the treatment of MB.

In the present study, we investigated the effect of curcumin on the proliferation of DAOY cells, and demonstrate its inhibitory effect on the Wnt/ $\beta$-catenin signaling pathway. Therefore, we hypothesized that curcumin inhibits cell proliferation by increasing the activity of GSK-3 $\beta$ and by inhibiting the Wnt/ $\beta$-catenin signaling pathway through nuclear $\beta$-catenin loss.

\section{Materials and methods}

Chemicals. Minimum Essential Medium (MEM/EBSS), fetal bovine serum (FBS) and penicillin-streptomycin solution were purchased from HyClone Laboratories (South Logan, UT, USA). OPTI-MEM was purchased from Life Technologies (Carlsbad, CA, USA). Curcumin [1,7-bis(4hydroxy-3-methoxyphenyl)-1,6-hepatadiene-3,5-dione; diferuloymethane] and MTT [3-(4,5-dimethylthiazol-2-yl)2,5-diphenyltetrazolium bromide] were purchased from Sigma-Aldrich (Bangalore, India).

Cell culture. The medulloblastoma cell line DAOY was a generous gift from Dr Xiuwu Bian (Institute of Pathology and Southwest Cancer Center, Southwest Hospital, Third Military Medical University, Chongqing, China). Cells were cultured in MEM containing 10\% FBS, $2 \mathrm{mM}$ glutamine, $100 \mu \mathrm{g} / \mathrm{ml}$ streptomycin, and $100 \mathrm{U} / \mathrm{ml}$ penicillin and aseptically grown at $37^{\circ} \mathrm{C}$ in a humidified incubator containing $5 \% \mathrm{CO}_{2}$.

Antibodies. Rabbit anti-human GSK-3 $\beta$ antibody $(27 \mathrm{C} 10$; Cell Signaling Technology, Danvers, MA, USA), rabbit antihuman phospho-GSK-3 $\beta$ (Ser9) antibody (5B3; Cell Signaling Technology), rabbit anti-human $\beta$-catenin monoclonal antibody (1247-1; Epitomics Inc., Burlingame, CA, USA), rabbit anti-human phospho- $\beta$-catenin (Ser37) antibody (11219-2; Signalway Antibody, College Park, MD, USA), rabbit antihuman cyclin D1 monoclonal antibody (2261-1; Epitomics) and rabbit anti-human histone $\mathrm{H} 2$ monoclonal antibody (3522-1; Epitomics) were used to detect the expression of the corresponding proteins. Rabbit anti-human $\beta$-actin polyclonal antibody (CW0097; CWBIO, Beijing, China) was used as an internal control. Peroxidase conjugated goat anti-rabbit IgG (GAR007; MultiSciences Biotech Co.) and fluorescein-conjugated Affinipure goat anti-rabbit IgG (ZF-0311; ZSGB-BIO, Beijing, China) were used as secondary antibodies.
Cell proliferation assay. The effect of curcumin on cell proliferation was assessed by MTT assay as previously described (15). DAOY cells were seeded in triplicate in 96-well plates at a density of 5,000/well and incubated overnight. Curcumin was dissolved in dimethyl sulfoxide (DMSO) and diluted in MEM. The cells were treated with varying concentrations $(0,20,40,60,80$ and $100 \mu \mathrm{M})$ of curcumin for 24,48 and $72 \mathrm{~h}$. After the indicated times, $10 \mu \mathrm{l}$ of the MTT solution was added to each well, and the plates were incubated for $4 \mathrm{~h}$ at $37^{\circ} \mathrm{C}$. The absorbance in individual wells was quantified using an enzyme-linked immunosorbent assay (ELISA) reader at $595 \mathrm{~nm}$.

Cell cycle analysis as detected by flow cytometry. In order to evaluate the effect of curcumin on the cell cycle, DAOY cells were treated with curcumin at a dose of $30 \mu \mathrm{M}$ for different time periods $(12,24$ and $48 \mathrm{~h})$. After the treatment, the cells were harvested by trypsinization, washed twice with ice-cold PBS, fixed with ice-cold $70 \%$ ethanol and maintained overnight at $-20^{\circ} \mathrm{C}$. DNA was stained with $100 \mu \mathrm{g} / \mathrm{ml}$ propidium iodide (PI) solution. The cell cycle distribution was analyzed by flow cytometry.

Immunofluorescence. For immunofluorescence, DAOY cells were cultured on glass coverslips in a 6-well plate and treated with curcumin $(30 \mu \mathrm{M})$ for $48 \mathrm{~h}$. Thereafter, the cells were washed with PBS [phosphate-buffered saline (0.01 M, pH 7.2)] and fixed in $4 \%$ paraformaldehyde for $15 \mathrm{~min}$ at room temperature. The coverslips were washed and permeablized for $10 \mathrm{~min}$ in $0.5 \%$ Triton X-100 followed by blocking with normal serum for $30 \mathrm{~min}$ at room temperature. The cells were then incubated with the anti- $\beta$-catenin antibody (1:100) overnight at $4^{\circ} \mathrm{C}$. Expression of $\beta$-catenin was evaluated using FITC-conjugated goat anti-rabbit antibody (1:100) and the cells were incubated for $1 \mathrm{~h}$ at $37^{\circ} \mathrm{C}$. Subsequently, cells were washed again with PBS and observed under a confocal laser microscope.

Western blot analysis. For protein analysis, DAOY cells were grown and treated with curcumin $(30 \mu \mathrm{M})$ for $48 \mathrm{~h}$. The cells were washed with PBS and then lysed in RIPA buffer [150 $\mathrm{mM}$ of $\mathrm{NaCl}, 1 \mathrm{mM}$ of EDTA, $1 \%$ Nonidet P-40, $0.5 \%$ sodium deoxycolate, $0.1 \% \mathrm{SDS}, 50 \mathrm{mM}$ of Tris- $\mathrm{HCl}(\mathrm{pH} 7.5)]$, containing protease inhibitors. Lysates were clarified by centrifugation $\left(14,000 \mathrm{x} \mathrm{g}\right.$ for $15 \mathrm{~min}$ at $\left.4^{\circ} \mathrm{C}\right)$; the supernatant was removed and stored at $-80^{\circ} \mathrm{C}$. Protein concentration was determined by BCA (bicinchoninic acid) and lysates were electrophoretically resolved on an 8-12\% SDS-PAGE and transferred onto a PVDF membrane. After blocking with $5 \%$ non-fat milk in Tris-buffered saline with $0.1 \%$ Tween-20 (TBST), membrances were incubated with respective primary antibodies directed against GSK-3 $\beta(1: 1,000)$, p-GSK-3 $\beta$ (Ser9) $(1: 1,000), \beta$-catenin $(1: 1,000), p-\beta$-catenin (Ser37) $(1: 300)$, cyclin D1 $(1: 1,000)$ and $\beta$-actin $(1: 3,000)$ at $4^{\circ} \mathrm{C}$ overnight. Membranes were washed and then incubated with HRP-conjugated rabbit anti-IgG $(1: 5,000)$ for $1 \mathrm{~h}$ at room temperature. Protein bands were assessed by enhanced chemiluminescence system (ECL; KeyGen, Nanjing, China) and quantitated using Quantitive One Image Analysis. The specific western blot process was performed according to the study by Wang et al (16). 

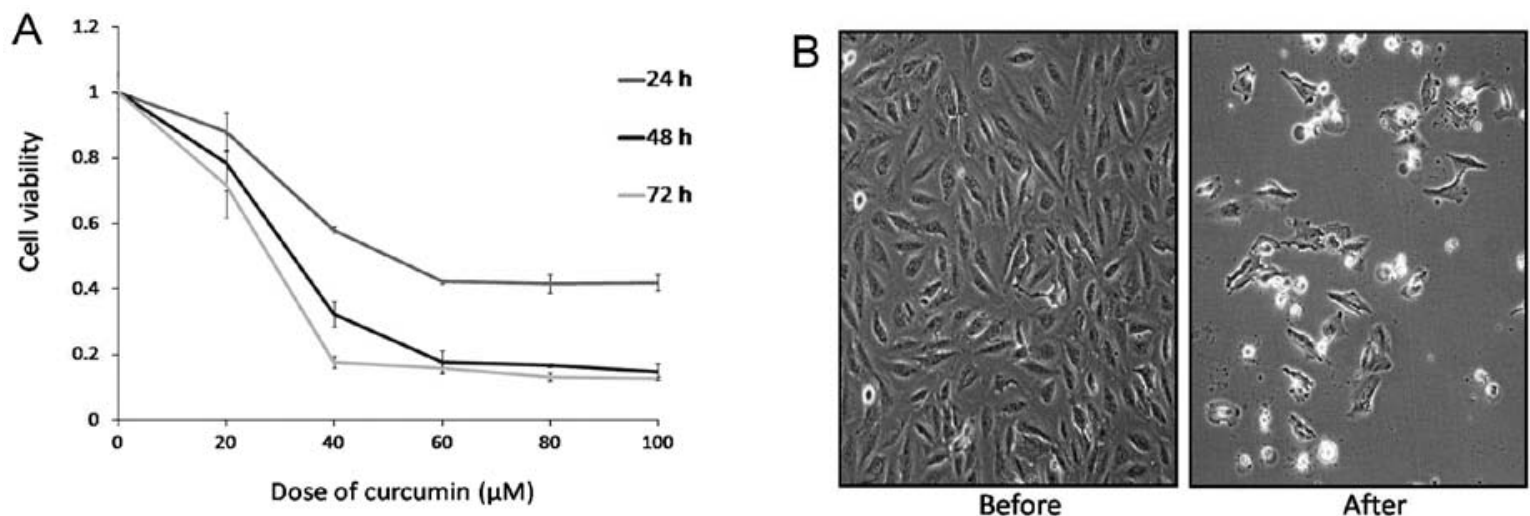

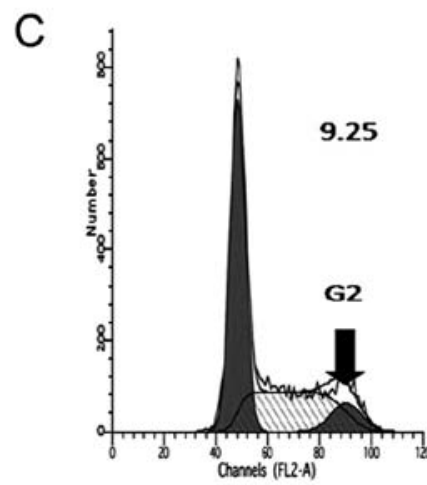

0

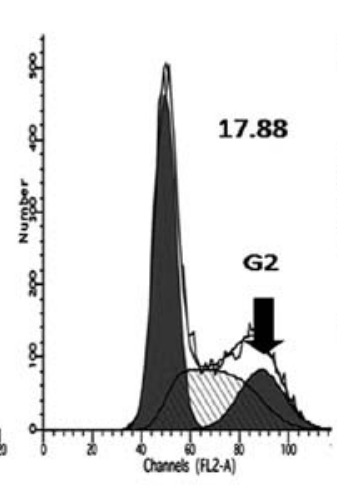

12

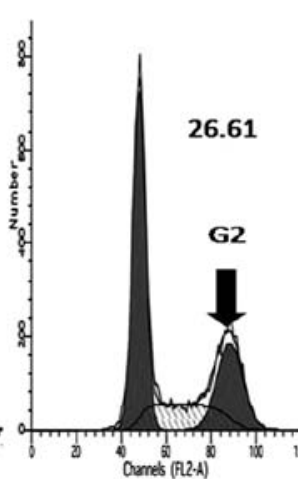

24

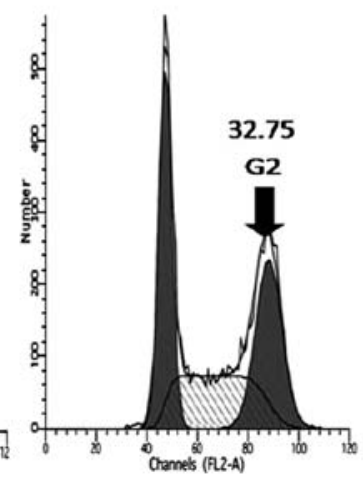

48

Figure 1. Antiproliferative effects of curcumin on medulloblastoma DAOY cells. (A) Cells were treated with different concentrations (as indicated) of curcumin for different time (as indicated). Cell viability was measured by MTT assay. Results are expressed as the mean \pm SD from 3 different experiments (P<0.05). (B) Representative images of the cells after treatment for $48 \mathrm{~h}$ with $30 \mu \mathrm{M}$ curcumin. (C) Cell cycle distribution was assessed by flow cytometry. The numbers in the boxes represent the proportions of $\mathrm{G}_{2} / \mathrm{M}$ phase cells

$R T-P C R$. Total RNA was extracted from DAOY cells using the TRIpurer Reagent (Bioteke Corp., Beijing, China). The RNA $(200 \mathrm{ng})$ was reverse transcribed (RT) into single-stranded cDNA using BioTeke Super RT kit according to the manufacturer's instructions (Bioteke Corp.). PCR amplification of target cDNAs, and an internal control (GAPDH) cDNA, was carried out using the specific primer pairs. The PCR cycling conditions used included a denaturation step at $94^{\circ} \mathrm{C}$ for $3 \mathrm{~min}$; 30 cycles of denaturation at $94^{\circ} \mathrm{C}$ for $30 \mathrm{sec}$, annealing at $58^{\circ} \mathrm{C}$ for $30 \mathrm{sec}$ and extension at $72^{\circ} \mathrm{C}$ for $30 \mathrm{sec}$; and a final extension at $72^{\circ} \mathrm{C}$ for $5 \mathrm{~min}$. The PCR products were separated by electrophoresis on a $1.5 \%$ agarose gel at $100 \mathrm{~V}$ for $30 \mathrm{~min}$. The sequences of the primers were as follow: GSK-3 $\beta$ (261 bp) forward, ATTTCCAGGGGATAGTGGTGTG and reverse, GTTAGTCGGGCAGTTGGTGTAT. $\beta$-catenin (305 bp) forward, GAACTGTCTTTGGACTCTCAGG and reverse, CCATCTCTGCTTCTTGGTGTC; cyclin D1 (175 bp) forward, CGGAGGAGAACAAACAGATCT and reverse, AGGCGGT AGTAGGCGGGT; GAPDH (542 bp) forward, GAGCCAA AAGGGTCATCATCTC and reverse, AAAGGTGGAGGA GTGGGTGTC.

Silencing of $\beta$-catenin by siRNA. The expression of $\beta$-catenin in DAOY cells was blocked using synthetic siRNA. The cells were plated in 6-well plates at a density of $3 \times 10^{5}$ cells/well and grown for $24 \mathrm{~h}$. The cells were transfected according to the manufacturer's directions using 200 pM synthetic siRNA duplexes (sense 5-GGACACAGCAGCAAUUUGUTT, antisense 5'-ACAAAUUGCUGCUGUGUCCTT; GenePharma) or negative control sense siRNA (sense 5'-UUCUCCGAACG UGUCACGUTT and antisense 5'-ACGUGACACGUUCGGA GAATT; GenePharma) for $24 \mathrm{~h}$ to silence $\beta$-catenin expression or using Lipofectamine 2000 reagent (Invitrogen, Carlsbad, CA, USA). Then DAOY cells were grown for $6 \mathrm{~h}$, and washed once with PBS and switched to $10 \%$ FBS media. After $24 \mathrm{~h}$, plates were replaced with 10\% FBS media or curcumin $(30 \mu \mathrm{M})$. Cell viability analysis was performed $48 \mathrm{~h}$ after treatment.

Statistical analysis. All data are expressed as means \pm SD; the homogeneity test for variance was evaluated using the SPSS 17.0 software. The significance of difference between the groups was analyzed using two-way ANOVA test or the two-tailed unpaired Student's t-test. A P-value $<0.05$ was considered to indicate a statistically significant result.

\section{Results}

Curcumin inhibits medulloblastoma cell proliferation. We investigated the effect of curcumin on DAOY cells using the MTT assay. The cells were incubated in the presence of varying concentrations of curcumin $(0-100 \mu \mathrm{M})$ for 24,48 and $72 \mathrm{~h}$, and then the effects of curcumin were measured. The MTT assay showed that curcumin treatment exhibited 
A

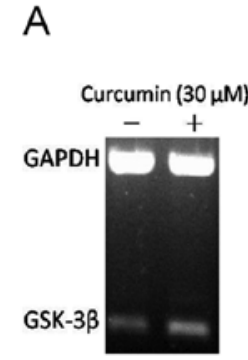

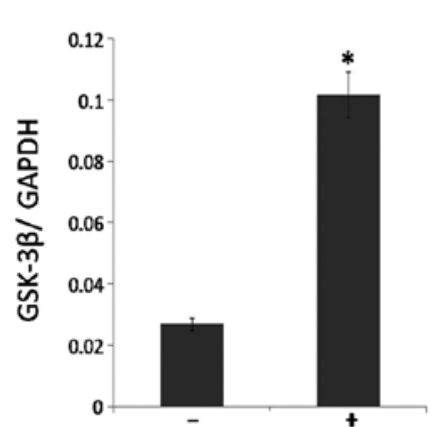

B

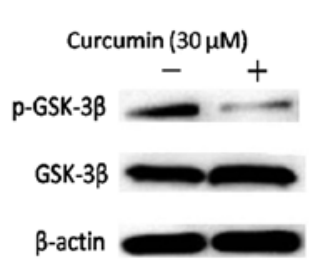

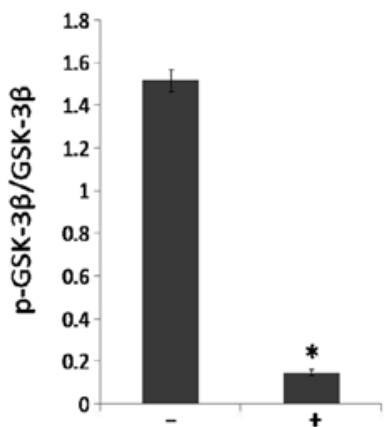

Figure 2. Effect of curcumin on the activation of GSK-3 $\beta$. (A) GSK-3 $\beta$ mRNA expression in cells treated with or without $30 \mu$ M curcumin. GAPDH was used as an internal control. The graph indicates that curcumin increased the expression of GSK-3 $\beta$. (B) The expression of GSK-3 $\beta$ protein and its phosphorylated form in cells treated with or without $30 \mu \mathrm{M}$ curcumin. The p-GSK-3 $\beta$ band intensities were normalized to total GSK-3 $\beta$ levels and graphed. Curcumin treatment had no effect on the expression of $\beta$-actin, while the expression of GSK-3 $\beta$ was significantly increased and p-GSK-3 $\beta$ was notably decreased. ${ }^{*}<<0.05$.

A

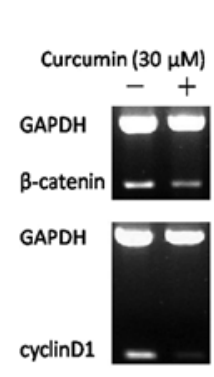

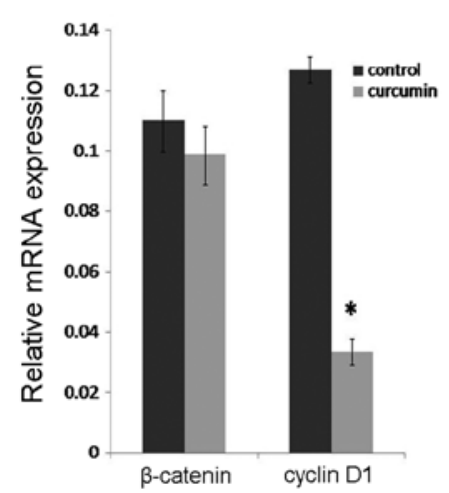

B

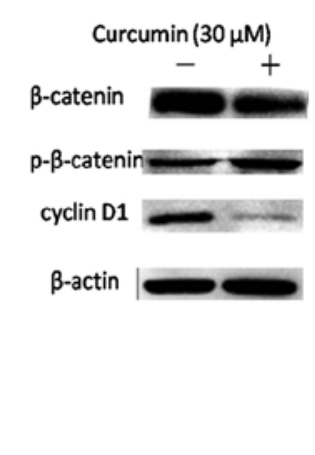

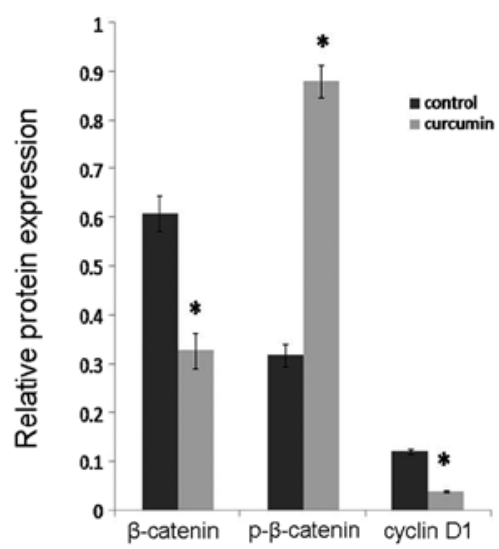

Figure 3. Curcumin treatment impairs Wnt/ $\beta$-catenin signaling. (A) mRNA expression of $\beta$-catenin and cyclin D1 in cells treated with or without $30 \mu \mathrm{M}$ curcumin. GAPDH was used as an internal control. The graph indicates that curcumin decreased the expression of cyclin D1, but had no effect on $\beta$-catenin. (B) The expression of cyclin D1 protein, $\beta$-catenin protein and its phosphorylated form in cells treated with or without $30 \mu \mathrm{M}$ curcumin. The protein band intensities were normalized to $\beta$-actin levels and graphed. Curcumin treatment had no effect on the expression of $\beta$-actin, while the expression of p- $\beta$-catenin was significantly increased and the cyclin D1 and $\mathrm{p}-\beta$-catenin were notably decreased. ${ }^{*} \mathrm{P}<0.05$.

dose- and time-dependent inhibition of cell growth (Fig. 1A). Curcumin had an 50\% antiproliferative effect on DAOY cells at an inhibitory concentration and time of $35 \mu \mathrm{M}$ and $48 \mathrm{~h}$. In addition, we observed that after $48 \mathrm{~h}$, curcumin-treated DAOY cells underwent morphological changes, such as cell rounding, shrinking, vacuolation and detachment (Fig. 1B). In order to explore the mechanism of the antiproliferation effect of curcumin on DAOY cells, the optimum cytostatic dose of $30 \mu \mathrm{M}$ of curcumin for $48 \mathrm{~h}$ was used.

To further study the effect of curcumin on the cell cycle, DAOY cells were analyzed by flow cytometry after 12, 24 and $48 \mathrm{~h}$ of treatment with $30 \mu \mathrm{M}$ curcumin. This showed that $17.88,26.61$ and $32.73 \%$ of cells reached the $G_{2} / M$ phase compared to $9.25 \%$ (control). There was a time-dependent increase of cells at the $\mathrm{G}_{2} / \mathrm{M}$ phase (Fig. 1C). This indicated that curcumin induced cell cycle arrest at the $G_{2} / M$ phase, which led to inhibition of proliferation.

GSK-3 $\beta$ is activated in curcumin-treated DAOY cells. GSK-3 $\beta$ is a negative regulator of the $\mathrm{Wnt} / \beta$-catenin signaling pathway. The main action of GSK-3 $\beta$ is to induce the phosphorylation of $\beta$-catenin and to inhibit its translocation to the cell nucleus. RT-PCR and western blot analysis assessed the action of curcumin in DAOY cells for activating GSK-3 $\beta$ function. In particular, curcumin treatment significantly increased the mRNA level of GSK-3 $\beta$ (Fig. 2A). At the protein level, the percentage between phospho-GSK-3 $\beta$ (inactive) and total GSK-3 $\beta$ was reduced following curcumin treatment compared to the control cells (Fig. 2B). These data revealed that curcumin treatment can induce the activation of GSK-3 $\beta$ in DAOY cells $(\mathrm{P}<0.05)$.

Curcumin suppresses the Wnt/ $\beta$-catenin signaling pathway in DAOY cells. $\beta$-catenin is a critical component of the Wnt signaling pathway and GSK-3 $\beta$ is known to affect $\beta$-catenin phosphorylation, thus, we investigated whether curcumin was able to inhibit the Wnt/ $\beta$-catenin signaling cascade by RT-PCR and western blot assay. The results showed that curcumin decreased the expression of $\beta$-catenin and increased p- $\beta$-catenin (inactive) at the protein level (Fig. 3B), but had no effect on $\beta$-catenin at the mRNA level (Fig. 3A). Together with the changes in $\beta$-catenin and $p-\beta$-catenin, the mRNA (Fig. 3A) and protein levels (Fig. 3B) of cyclin D1 were markedly decreased after curcumin treatment. All of these changes suggest that curcumin has a prominent inhibitory effect on the Wnt/ $\beta$-catenin signaling pathway. 
A

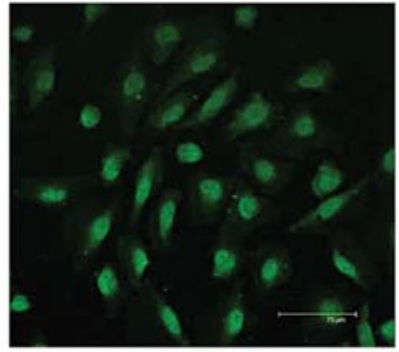

Before

B

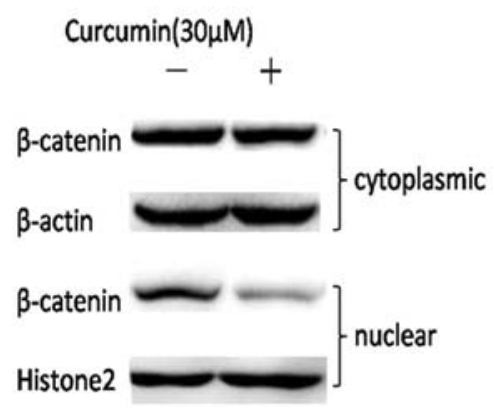

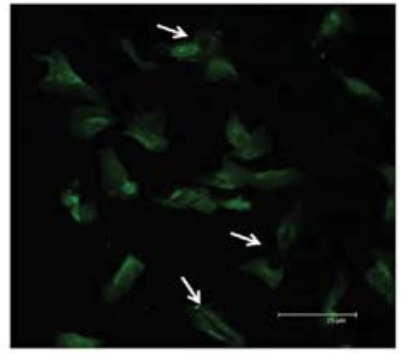

After

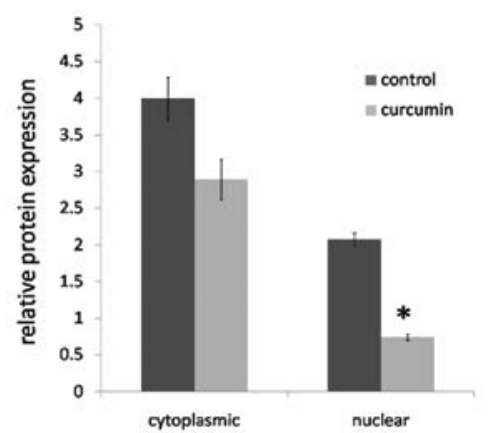

Figure 4. Effect of curcumin on the localization and nuclear expression of $\beta$-catenin in DAOY cells. (A) Expression of $\beta$-catenin in cells treated with or without curcumin $(30 \mu \mathrm{M})$ for $48 \mathrm{~h}$. There was high $\beta$-catenin staining located in the nucleus of the untreated cells. After treatment of curcumin, little $\beta$-catenin was located in the cytoplasm and the nucleus, even absent in some cell nuclei (arrows). (B) Cytoplasmic and nuclear protein extracts prepared from untreated or curcumin $(30 \mu \mathrm{M})$-treated cells were examined by immunoblotting. $\beta$-actin and Histone2 served as the cytoplasmic and nuclear loading control, respectively. Each sample was quantified densitometrically and normalized to the expression of $\beta$-actin and Histone2, respectively. Curcumin treatment had no effect on the expression of cytoplasmic $\beta$-catenin, while the expression of nuclear $\beta$-catenin was significantly decreased. ${ }^{\text {" }} \mathrm{P}<0.05$.

A

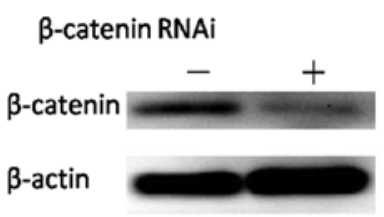

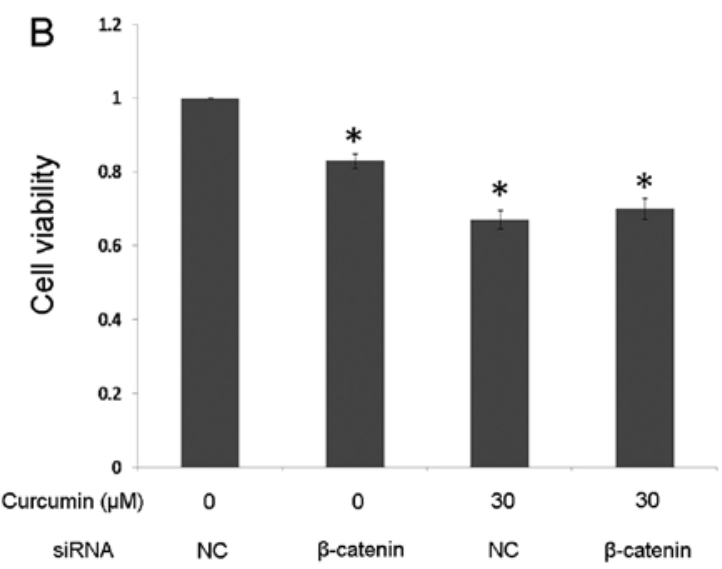

Figure 5. $\beta$-catenin is required for curcumin-mediated antiproliferation. (A) Silencing of $\beta$-catenin by $\beta$-catenin-specific siRNA. The $\beta$-catenin level was normalized to the $\beta$-actin level. Immunoblotting indicates $>75 \%$ suppression of $\beta$-catenin expression following transfection with the $\beta$-catenin-specific siRNA. (B) Cells were transfected with $\beta$-catenin-specific siRNA or negative control siRNA (NC), and then treated with FBS or curcumin (30 $\mu \mathrm{M})$ for $48 \mathrm{~h}$. Cell viability was measured by MTT assay. Results are expressed as the means \pm SD. The addition of curcumin to cells already depleted of $\beta$-catenin did not cause significant additional cell death. ${ }^{*} \mathrm{P}<0.05$; ns, not significant.

Curcumin inhibits Wnt/ $\beta$-catenin signaling through nuclear $\beta$-catenin loss. The above results showed that curcumin inhibits the activation of the $\mathrm{Wnt} / \beta$-catenin signaling pathway. Since the nuclear translocation of $\beta$-catenin is a key event in activation of the $\mathrm{Wnt} / \beta$-catenin signaling pathway, we checked the effect of curcumin on the expression of nuclear $\beta$-catenin. Immunofluorescence and western blot assays in DAOY cells were carried out to determine the location of $\beta$-catenin. After curcumin treatment, the cytoplasmic and nuclear expression levels of $\beta$-catenin were decreased, particularly in the nucleus $(\mathrm{P}<0.05)$ (Fig. 4).

Curcumin mediates the antiproliferation of DAOY cells dependent on the downregulation of $\beta$-catenin. $\beta$-catenin is the key regulator of the Wnt signaling pathway, which is a major event in the equilibrium between cell proliferation and cell death, and, therefore, it is implicated in the development of the cerebellar tumor medulloblastoma. Thereby, we sought 
to determine the role of $\beta$-catenin in the curcumin-mediated antiproliferation of DAOY cells. We transiently reduced $\beta$-catenin expression in DAOY cells using siRNA. Western blot analysis confirmed a $>75 \%$ decrease in $\beta$-catenin expression in the DAOY cells compared with the negative control siRNA (Fig. 5A). If downregulation of $\beta$-catenin is a critical antiproliferation mechanism of curcumin, one would predict that in the context of already-reduced $\beta$-catenin, curcumin treatment would not cause a significant additional increase in the antiproliferation effect. After inhibition of $\beta$-catenin expression, DAOY cells were exposed to $30 \mu \mathrm{M}$ curcumin, and cell proliferation was assayed by MTT. In the negative control siRNA-transfected group, curcumin treatment efficiently inhibited cell growth compared to the control group. In the $\beta$-catenin siRNA-transfected group, this decrease in $\beta$-catenin expression was associated with a significant reduction in the percentage of cell viability, but there was no significant difference in cell proliferation after curcumin treatment (Fig. 5B). These data strongly indicate that curcumin-mediated antiproliferation of DAOY cells is dependent on the downregulation of $\beta$-catenin.

\section{Discussion}

Medulloblastoma is a multifactorial disease, characterized by a disorder of signaling pathways at multiple steps (8). Treatment for MB remains highly problematic. The ineffectiveness, lack of safety, and high cost of chemoradiotherapy have limited their use in MB management. For this reason, major emphasis is being given to the development of multi-targeted drugs (1). In the present study, curcumin was shown that it could constitute a potent anti-medulloblastoma agent. Firstly, curcumin has an outstanding safety profile. In fact, different phase I and II clinical trials have shown that curcumin is safe for children and adults (17). Secondly, studies of curcumin in various central nervous system (CNS) disorders including Alzheimer's, Parkinson's, and stroke showed the potent effect of orally delivered curcumin in the brain (18). Due to the less accessible anatomic location of MB, when drugs cannot cross the blood brain barrier (BBB) it limits their inclusion in any chemotherapeutic protocol. Therefore, the treatment will be more effective and there will be less neurotoxic injury if the biological agents can cross the BBB. A recent study showed that curcumin crossed the BBB and inhibited tumor growth in orthotopic glioblastoma models (19). Finally, curcumin had potential antitumor effects in a variety of cancers (5), including MB. Curcumin has effects on multiple levels within the transcriptional network to restrict MB growth (20). Curcumin was reported to downregulate bcl-2 and bcl-xl, reduce histone deacetylase (HDAC) 4 expression and activity inhibiting MB cell proliferation. Curcumin inhibited the Shh-Glil signaling pathway by downregulating Shh protein. In in vivo medulloblastoma xenografts, curcumin reduced tumor growth and significantly increased survival in $\mathrm{Smo} / \mathrm{Smo}$ transgenic $\mathrm{MB}$ mouse model $(20,21)$. Although, multiple biological functions have been attributed to curcumin, the prime driving mechanism underlying its action remains to be clarified.

Gene-expression profiling studies have identified four molecular subgroups of MB associated with a different genetic profile, different activation of oncogenic pathways and distinct clinical outcomes (12). Thus, the activation of the Wnt/ $\beta$ catenin, Shh, Notch and Akt/NF-kB signaling pathways play key roles in different subgroups of MB. These pathways are differentially activated in different subsets of $\mathrm{MB}$, but engage in considerable crosstalk and cooperation $(8,22)$. Wnt-activated tumors are an independent molecular subgroup in MB which are characterized by a distinct pattern of genomic aberrations. Additional studies have identified activation of the Wnt/ $\beta$ catenin pathway in $25 \%$ MBs with the majority associated with activating mutations in $\beta$-catenin (23). Recently, studies show that inhibition of the Akt/NF- $\mathrm{kB}$ signaling pathway can affect Wnt/ $\beta$-catenin signaling, thus, resulting in cytoplasmatic retention of $\beta$-catenin (24). The $\mathrm{Wnt} / \beta$-catenin signaling is also required for $\mathrm{Hh}$ pathway-driven tumorigenesis (25). Inhibition of the $\mathrm{Wnt} / \beta$-catenin signaling pathway can impair MB growth in vitro and in vivo (26). Due to the wide involvement of the Wnt/ $\beta$-catenin signaling pathway in MB, inhibition of this pathway can be considered as an attractive target for MB.

In the present study, we investigated the antitumor activity of curcumin on DAOY cells and demonstrated that curcumin exerted multiple modulatory effects on the $\mathrm{Wnt} / \beta$-catenin signaling pathway components GSK-3 $\beta, \beta$-catenin and cyclin D1. In the present study our data suggest that curcumin can inhibit cell proliferation of MB cells by enabling the arrest of the cell cycle at the $\mathrm{G}_{2} / \mathrm{M}$ phase. Moreover, our results also showed that inhibition of Wnt/ $\beta$-catenin signaling pathway through nuclear $\beta$-catenin loss may be one of the mechanisms implicated in the suppression of cell proliferation in MB by curcumin.

Curcumin is known to be a good inhibitor of the Wnt $/ \beta$ catenin signaling pathway in gastric, colon, intestinal and prostatic cancer cell lines (27). Studies also exist on the downregulation of $\beta$-catenin in MB cells (20). However, the detailed molecular mechanisms of curcumin-mediated reduction of $\beta$-catenin are not fully understood.

GSK-3 $\beta$ is a kinase loaded with serine (Ser) and threonine (Thr). The phosphorylation or dephosphorylation of Ser9 is an important gating switch for regulating the activity of GSK-3 $\beta$ (28). It is also an important regulator in the Wnt/ $\beta$-catenin signaling pathway, and plays an important role in the proliferation and differentiation of progenitor cells during brain development (29). In the canonical Wnt signaling pathway, activated GSK-3 $\beta$ phosphorylates and translocates nuclear $\beta$-catenin from the nucleus to the cytoplasm resulting in the inhibition of the subsequent activation of $\mathrm{T}$ cell factor 4 (TCF4)-dependent gene transcription (such as cyclin D1 and c-Myc) (30). That is to say GSK-3 $\beta$ regulates $\beta$-catenin by controlling its protein level and nuclear localization. In particular, most of the Wnt pathway mutations reported in sporadic MBs target residues of serine 33 and 37 of $\beta$-catenin, which prevent phosphorylation-dependent degradation of $\beta$-catenin by GSK-3 $\beta$. As a consequence, $\beta$-catenin levels are increased in an uncontrolled manner, leading to the development of a transformed phenotype (31). In the present study, our data showed for the first time that curcumin attenuates the Wnt $/ \beta$-catenin signaling in MB cells by promoting phosphorylation-dependent degradation of $\beta$-catenin by GSK- $3 \beta$. Thus, it is no surprise that after curcumin treatment the changes in $\beta$-catenin were only at the protein level, not the mRNA level. The reason might be that the GSK-3 $\beta$-mediated effect 
of curcumin on $\beta$-catenin is more important than the direct effect of curcumin on $\beta$-catenin in MB. But more evidence confirming this hypothesis needs to be found.

Cyclin D1 is an oncoprotein that plays a key role in the development of MB (32). High expression of cyclin D1 is considered to be indicative of a poor prognosis as it is related to an unfavorable therapeutic outcome. Morever, overexpression of cyclin D1 protein leads to increased cell proliferation, which gives neoplastic cells a growth advantage and may also favor the occurrence of additional genetic lesions with potential oncogenic effects (33). Here, we showed that suppression of the nuclear translocation of $\beta$-catenin resulted in the decreased expression of cyclin D1, a downstream oncogene of the Wnt/ $\beta$-catenin signaling pathway. We also showed that curcumin effectively inhibited MB cell proliferation in vitro.

Through mechanistic studies, we found that curcumin promoted the activity of GSK-3 $\beta$, enhanced GSK-3 $\beta$ binding to $\beta$-catenin, increased the phosphorylation of $\beta$-catenin, and reduced the levels of nuclear $\beta$-catenin and cyclin D1, suggesting that curcumin could inactivate $\mathrm{Wnt} / \beta$-catenin signaling to suppress the proliferation of MB cells. Our study found that the viability of $\mathrm{MB}$ cells was attenuated after $\beta$-catenin was silenced. This verified that $\beta$-catenin has an important role in the onset and maintainance of MB. Yet, the antiproliferation following the silencing of $\beta$-catenin was found to be weaker than the treatment of curcumin. This phenomenon may occur due to the following reasons. On the one hand, Wnt-activated signals undergo crosstalk with additional signaling pathways, for example, those of Hh (34), TGF (35) and Notch (36), which play important roles in the development of MB. Curcumin modulates various molecular targets including transcription factors, growth factors and their receptors, cytokines, enzymes, and genes regulating cell proliferation and apoptosis (5). Thus, there may be other mechanisms involved in the antiproliferative effect of curcumin.

In conclusion, these findings provide evidence that the inhibitory effect of curcumin on cell proliferation involves the inhibition of the $\mathrm{Wnt} / \beta$-catenin pathway by activating GSK-3 $\beta$, attenuating the $\mathrm{Wnt} / \beta$-catenin pathway via reducing nuclear $\beta$-catenin, accompanied by the downregulation of cyclin D1, which is tightly connected to the development and prognosis of MB. Thus, curcumin has the potential to be developed as a safe therapeutic for medulloblastoma. Further studies are needed to verify the antitumor ability of curcumin in vivo.

\section{Acknowledgements}

The present study was supported by funds from the National Science Foundation of China (NSFC: 81272571).

\section{References}

1. de Bont JM, Packer RJ, Michiels EM, den Boer ML and Pieters R: Biological background of pediatric medulloblastoma and ependymoma: a review from a translational research perspective. Neuro Oncol 10: 1040-1060, 2008.

2. Lin J, Zheng Y, Chen K, Huang Z, Wu X and Zhang N: Inhibition of FOXM1 by thiostrepton sensitizes medulloblastoma to the effects of chemotherapy. Oncol Rep 30: 1739-1744, 2013.

3. Maheshwari RK, Singh AK, Gaddipati J and Srimal RC: Multiple biological activities of curcumin: a short review. Life Sci 78 2081-2087, 2006.
4. Anand P, Sundaram C, Jhurani S, Kunnumakkara AB and Aggarwal BB: Curcumin and cancer: an 'old-age' disease with an 'age-old' solution. Cancer Lett 267: 133-164, 2008.

5. Kunnumakkara AB, Anand P and Aggarwal BB: Curcumin inhibits proliferation, invasion, angiogenesis and metastasis of different cancers through interaction with multiple cell signaling proteins. Cancer Lett 269: 199-225, 2008.

6. Dorai T, Cao YC, Dorai B, Buttyan R and Katz AE: Therapeutic potential of curcumin in human prostate cancer. III. Curcumin inhibits proliferation, induces apoptosis, and inhibits angiogenesis of LNCaP prostate cancer cells in vivo. Prostate 47: 293-303, 2001.

7. Gilbertson RJ and Ellison DW: The origins of medulloblastoma subtypes. Annu Rev Pathol 3: 341-365, 2008.

8. Guessous F, Li Y and Abounader R: Signaling pathways in medulloblastoma. J Cell Physiol 217: 577-583, 2008.

9. Angers S and Moon RT: Proximal events in Wnt signal transduction. Nat Rev Mol Cell Biol 10: 468-477, 2009.

10. Roussel MF and Hatten ME: Cerebellum development and medulloblastoma. Curr Top Dev Biol 94: 235-282, 2011.

11. Reya $\mathrm{T}$ and Clevers $\mathrm{H}$ : Wnt signalling in stem cells and cancer. Nature 434: 843-850, 2005.

12. Northcott PA, Korshunov A, Witt H, Hielscher T, Eberhar CG, Mack S, Bouffet E, Clifford SC, Hawkins CE, French P, Rutka JT, Pfister S and Taylor MD: Medulloblastoma comprises four distinct molecular variants. J Clin Oncol 29: 1408-1414, 2011.

13. Thompson MC, Fuller C, Hogg TL, Dalton J, Finkelstein D, Lau CC, Chintagumpala M, Adesina A, Ashley DM, Kellie SJ, Taylor MD, Curran T, Gajjar A and Gilbertson RJ: Genomics identifies medulloblastoma subgroups that are enriched for specific genetic alterations. J Clin Oncol 24: 1924-1931, 2006.

14. Koch A, Hrychyk A, Hartmann W, Waha A, Mikeska T, Schuller U, Sorensen N, Berthold F, Goodyer CG, Wiestler OD, Birchmeier W, Behrens J and Pietsch T: Mutations of the Wnt antagonist AXIN2 (Conductin) result in TCF-dependent transcription in medulloblastomas. Int J Cancer 121: 284-291, 2007.

15. Sun P, Liu Y, Ying $\mathrm{H}$ and Li S: Action of db-cAMP on the bystander effect and chemosensitivity through connexin 43 and Bcl-2-mediated pathways in medulloblastoma cells. Oncol Rep 28: 969-976, 2012

16. Wang X, Shi Q, Xu K, Gao C, Chen C, Li XL, Wang GR, Tian C, Han J and Dong XP: Familial CJD associated PrP mutants within transmembrane region induced $\mathrm{Ctm}-\mathrm{PrP}$ retention in ER and triggered apoptosis by ER stress in SH-SY5Y cells. PLoS One 6: e14602, 2011.

17. Goel A, Kunnumakkara AB and Aggarwal BB: Curcumin as 'Curecumin': from kitchen to clinic. Biochem Pharmacol 75: 787-809, 2008.

18. Cole GM, Teter B and Frautschy SA: Neuroprotective effects of curcumin. Adv Exp Med Biol 595: 197-212, 2007.

19. Perry MC, Demeule M, Regina A, Moumdjian R and Beliveau R: Curcumin inhibits tumor growth and angiogenesis in glioblastoma xenografts. Mol Nutr Food Res 54: 1192-1201, 2010.

20. Elamin MH, Shinwari Z, Hendrayani SF, Al-Hindi H, Al-Shail E, Khafaga Y, Al-Kofide A and Aboussekhra A: Curcumin inhibits the Sonic Hedgehog signaling pathway and triggers apoptosis in medulloblastoma cells. Mol Carcinog 49: 302-314, 2010.

21. Lee SJ, Krauthauser C, Maduskuie V, Fawcett PT, Olson JM and Rajasekaran SA: Curcumin-induced HDAC inhibition and attenuation of medulloblastoma growth in vitro and in vivo. BMC Cancer 11: 144, 2011.

22. Baryawno N, Sveinbjornsson B, Kogner P and Johnsen JI: Medulloblastoma: a disease with disorganized developmental signaling cascades. Cell Cycle 9: 2548-2554, 2010.

23. Rogers HA, Miller S, Lowe J, Brundler MA, Coyle B and Grundy RG: An investigation of WNT pathway activation and association with survival in central nervous system primitive neuroectodermal tumours (CNS PNET). Br J Cancer 100: 1292-1302, 2009.

24. Baryawno N, Sveinbjornsson B, Eksborg S, Chen CS, Kogner P and Johnsen JI: Small-molecule inhibitors of phosphatidylinositol 3-kinase/Akt signaling inhibit Wnt/3-catenin pathway cross-talk and suppress medulloblastoma growth. Cancer Res 70: 266-276, 2010.

25. Rogers HA, Sousa S, Salto C, Arenas E, Coyle B and Grundy RG: WNT/ $\beta$-catenin pathway activation in Myc immortalised cerebellar progenitor cells inhibits neuronal differentiation and generates tumours resembling medulloblastoma. Br J Cancer 107: 1144-1152, 2012. 
26. Cimmino F, Scoppettuolo MN, Carotenuto M, De Antonellis P, Dato VD, De Vita G and Zollo M: Norcantharidin impairs medulloblastoma growth by inhibition of $\mathrm{Wnt} / \beta$-catenin signaling. J Neurooncol 106: 59-70, 2012.

27. Sundram V, Chauhan SC, Ebeling M and Jaggi M: Curcumin attenuates $\beta$-catenin signaling in prostate cancer cells through activation of protein kinase D1. PLoS One 7: e35368, 2012.

28. Frame S, Cohen P and Biondi RM: A common phosphate binding site explains the unique substrate specificity of GSK3 and its inactivation by phosphorylation. Mol Cell 7: 1321-1327, 2001

29. Mao Y, Ge X, Frank CL, Madison JM, Koehler AN, Doud MK Tassa C, Berry EM, Soda T, Singh KK, Biechele T, Petryshen TL, Moon RT, Haggarty SJ and Tsai LH: Disrupted in schizophrenia 1 regulates neuronal progenitor proliferation via modulation of GSK3 $\beta / \beta$-catenin signaling. Cell 136: 1017-1031, 2009.

30. Wu G, Huang H, Garcia Abreu J and He X: Inhibition of GSK3 phosphorylation of $\beta$-catenin via phosphorylated PPPSPXS motifs of Wnt coreceptor LRP6. PLoS One 4: e4926, 2009.
31. Raffel C: Medulloblastoma: molecular genetics and animal models. Neoplasia 6: 310-322, 2004.

32. Jozwiak J, Grajkowska W and Wlodarski P: Pathogenesis of medulloblastoma and current treatment outlook. Med Res Rev 27: 869-890, 2007.

33. Zhao X, Song T, He Z, Tang L and Zhu Y: A novel role of cyclinD1 and p16 in clinical pathology and prognosis of childhood medulloblastoma. Med Oncol 27: 985-991, 2010.

34. Mimeault $\mathrm{M}$ and Batra SK: Frequent deregulations in the hedgehog signaling network and cross-talks with the epidermal growth factor receptor pathway involved in cancer progression and targeted therapies. Pharmacol Rev 62: 497-524, 2010.

35. Guoand X and Wang XF: Signaling cross-talk between TGF- $\beta /$ BMP and other pathways. Cell Res 19: 71-88, 2009.

36. Li C, Zhang Y, Lu Y, Cui Z, Yu M, Zhang S and Xue X: Evidence of the cross talk between Wnt and Notch signaling pathways in non-small-cell lung cancer (NSCLC): Notch3-siRNA weakens the effect of $\mathrm{LiCl}$ on the cell cycle of NSCLC cell lines. J Cancer Res Clin Oncol 137: 771-778, 2011. 